PostgRAD. MED. J., (1966), 42, 386

Current Survey

\title{
RESPIRATORY PROBLEMS OF THE NEW-BORN INFANT
}

\author{
J. A. Davis, M.B., B.S., M.R.C.P. \\ Senior Lecturer, Institute of Child Health, Hammersmith Hospital, London, W.12
}

THE dramatic fall in late infant mortality in industrialised countries that began a century or so ago was not initially accompanied by any considerable drop in perinatal mortality which, even today, still represents a very high proportion of all deaths in childhood. For this reason, research in paediatrics bad tended in recent years to focus on the diseases of the new-born infant and in particular (because they are responsible for the major part of the mortality and morbidity) on those conditions that cause respiratory failure in the first week of life. The findings of the Perinatal Mortality Survey conducted by The National Birthday Trust in 1958 show that almost twothirds of the whole early neonatal mortality occurs in the 7 per cent or so of infants who weigh less than $2,500 \mathrm{~g}$. at birth (and are thus by definition premature), and that amongst these infants respiratory disorders are responsible for almost 50 per cent of the total deaths. There is also a considerable morbidity in survivors. Contrary to uninformed opinion, birth asphyxia per se is a relatively uncommon cause of death in infants born alive; on the other hand still-born infants, of whom a high proportion are found to be under weight for dates and to have died of intrauterine asphyxia during labour, comprise a high proportion of the whole perinatal mortality.

Respiratory failure in babies born alive is in great measure due to the following conditions.

(1) Congenital malformations that interfere with respiration.

(2) The so-called idiopathic respiratory distress syndrome of the premature infant.

(3) Pneumonia.

(4) Recurrent apnoea.

(5) Miscellaneous conditions.

These will be considered in turn although in practice they often co-exist.

\section{(1) Congenital Malformations}

Those congenital malformations that affect the respiratory tract usually present soon after birth with rather characteristic signs.

The clinical syndromes to which they give rise are easily recognised by a trained observer and in most cases the malformations concerned are amenable to surgical treatment if the diagnosis has been made before irreversible damage has occurred.

\section{Choanal Atresia}

To be able to breathe through the nose is vital to the new-born infant, who can only mouth breathe when crying: complete blockage of the posterior choanae therefore manifests itself by apparent respiratory obstruction with retraction and cyanosis which is completely relieved by crying only to recur when normal breathing is resumed. The condition can be confirmed by an attempt to pass a tube down the nostrils into the nasopharynx and is best treated by immediate endotracheal intubation while awaiting the assistance of an experienced ENT surgeon. It is rare.

\section{The Pierre Robin Syndrome}

In this condition the lower jaw is "underslung" with the result that when the infant lies supine the tongue falls back, as in the unconscious patient, occluding the airway; in addition there is often a midline cleft in the palate in which the tongue may impaot. The characteristic chinless facies is not always recognised until the infant is found dead with the stigmata of acute asphyxia or has suffered brain damage from a series of asphyxial crises. Such infants should be nursed prone and should be kept under constant surveillance during the first weeks of life. The insertion of an airway is a useful safety measure, and particular care has to be taken with feeds. The abnormal position of the jaw is probably due to pressure in utero and with time is self-correcting though when there is a cleft palate this will require operative treatment. The condition is relatively rare.

\section{Abnormalties of the Larynx}

These are characterised by an abnormal cry (hoarseness or voicelessness) and signs of respiratory obstruction. The affected infant is liable to die suddenly and an emergency tracheostomy should be carried out if intubation is impracticable prior to transfer to a suitable surgical centre. Among the abnormalities described are stenosis, webbing. haemangioma, extreme laxity and various benign tumours.

\section{Abnormalities of the Trachea}

Of these the commonest in the presence of a "vascular ring" around the trachea and oesophagus due to an abnormal arrangement of the great vessels. The posterior tracheal wall being unpro- 
tected by cartilage, the passage of milk down the oesophagus tends to cause respiratory obstruction, with retraction, cyanosis and coughing during feeds, and there is often stridor and apparent obstruction between feeds particularly when the head and neck are held in a flexed position. Surgical trealtment is seldom either necessary or feasible, but the child may have to be tube fed for some weeks. The author has seen infantile autism as a late complication.

\section{The So-called Tracheo-oesophageal Fistula}

The commonest variety of this malformation comprises upper oesophageal atresia with a communication between the lower oesophagus and trachea. Fortunately this is also the variety which is easiest to recognise and most amenable to surgical treatment. It is a relatively common condition, occurring in about $1: 4000$ births, and is often associated with maternal hydramnios.

The oesophageal atresia makes it impossible for the infan't to swallow his secretions and as a result he is "bubbly" from birth despite frequent sucking out. The communication between the trachea and lower oesphagus results in overfilling of the intestinal tract with air, and therefore in resonant abdominal distension. Clinical diagnosis can be confirmed by the attempted passage of a tube into the stomach, where its presence should be confirmed by auscultation or aspiration.

Once the diagnosis is made the infant should be transferred immediately to a suitable centre for operation, provision being made for continuous suction and the maintenance of body temperature en route. The infant should not of course be fed. It may be necessary to intubate the larynx to ensure safe transit but unless the diagnosis has been made very late and the infant has become very dehydrated the administration of I.V. fluids is unnecessary. The passage of umbilical arterial and venous catheters is of assistance in monitoring blood gas tensions and for the giving of a transfusion at operation should this be required.

\section{Diaphragmatic Hernia}

This is also a relatively common malformation, being found in approximately 1:8000 deliveries. In many cases it results in fatal birth asphyxia but less commonly the affected infant may survive hours, days, weeks or months without treatment. The presence of liver and gut in the thoracic cavity causes intermittent cyanosis and respiratory difficulties, especially during and after feeds, and may also induce cardiac embarrassment and irregularity by producing large and sudden shifts of the mediastinum. Careful auscultation will sometimes enable a clinical diagnosis to be made, but the condition is usually recognised by $\mathrm{X}$-ray examination. The treatment is surgical and affected infanits should be itransferred to a paediatric surgical centre as soon as the diagnosis has been confirmed, no oral feeds being given en route. In severe cases the baby should be nursed in high concentrations of oxygen so that the gut does not3 become distended with unabsorbable nitrogen. $\stackrel{\perp}{\varrho}$ Again the passage of catheters into both sets of $c$ umbilical vessels will facilitate investigation, $\vec{F}$ monitoring and treatment.

(2) The Idiopathic Respiratory Distress Syndrome $\frac{\bar{C}}{\circ}$

This is the single most important respiratory $\frac{\overline{\bar{F}}}{\frac{\mathrm{c}}{2}}$ disease of the new-born infant, having both a $\mathbb{\otimes}$ high incidence and a high mortality. It affects predominantly infants of low birth weight and ${ }^{\infty}$ early gestational age, but about 10 per cent of $\overrightarrow{0}$ cases are full-term infants, while infants of very low gestational age seem to be relatively less $\vec{\omega}$ susceptible than those of 31-37 weeks gestation? and of 1000-2000 g. birth weight. Full-termo babies of low birth-weight are seldom affected 3 whereas the incidence is high in the often high $\vec{N}$ birth-weight prematurely delivered infants of dia- $A$ betic mothers. There is disagreement on whether $\infty_{\infty}^{\infty}$ the association with delivery by caesarean section $\omega$ is real or apparent, some authors maintaining ${ }^{\infty}$ that conditions leading to operative delivery, such 을 as antepartum haemornhage, by themselves pre- dispose to respiratory distress, others that the $\vec{c}$ incidence is also high in babies delivered by elective section before the 36th-37th week of ${ }^{\oplus}$ gestation. The author's opinion is that these dif $\vec{\bullet}$ ferences in experience are probably the resulf of differences in the technique of section in dif ferent centres; there being evidence that generg anaesthesia in the mother protects against the development of respiratory distress in the infant, whereas regional anaesthesia may predispose to it. \% Other factors in the aetiology are erythroblastosis $\stackrel{\mathbb{Q}}{\Omega}$ foetalis, birth asphyxia and twinning: indeed $\overrightarrow{\vec{P}}$ Potter has shown that the differential mortality 3 between twins is entirely accounted for by the $\frac{3}{\sqrt{3}}$ higher mortality from respiratory distress of the second twin.

Thus the development of respiratory distress appears to be connected with two principal factors: (i) Delivery before term, and (ii) Intrauterine asphyxia; and it is therefore of interest that these two factors have also been shown to be concerned in the induction of respiratory distress in new-born animals.

\section{Pathology}

The pathological features found in the lungs of babies dying of progressive dyspnoea, which $\sigma$ comprise oedema, atelectasis and haemorrhage as $\mathrm{N}$ well as hyaline membrane formation, have been $N$ grouped together under the title "The Pulmonary $\mathrm{w}$ Syndrome of the Newborn". The presence in the lung of oedema, congestion and atelectasis may well prove to be more significant than hyaline membrane formation as pointers to the aetiology. Recently much attention has been given to the cause of the extensive alveolar collapse that is such a consistent feature of the lungs of premature infants coming to post mortem. Deflation is 
often so complete that the lungs resemble liver, sinking in water, and an inexperienced pathologist may find it difficult to believe that they have ever been expanded. To some exten't this phenomenon can be explained by the fact that distressed babies are usually nursed in high concentrations of oxygen; for in such circumstances apnoea winl result in the absorption by the blood of nearly all the gas content of each alveolus; yet the lungs of mature babies dying in the same conditions seldom collapse completely, and complete collapse is sometimes seen in premature infants not given oxygen in concentrations higher than 30 per cent.

It has now been established that this tendency to deflation is due to a deficiency of a factor extractable from normal lungs that has the property of lowering surface tension. This factor normally appears in the foetal lung at about 25 weeks gestation with the disintegration of the alveolar epithelium, but it is missing from the lungs of more mature infants dying of progressive dyspnoea. The presence or absence of this agent in a given lung sample can be assessed in three ways: first, by expressing bubbles from the lung and measuring their stability; secondly, by measuring the surface tension of lung extracts under controlled conditions; thirdly by plotting the hysteresis loops of excised lungs mechanically inflated with gas. The substance concerned is a lipo-protein containing dipalmitoyl, diphosphatidoyl lecithin and its activity is the result of its forming a film at the gas-fluid interspace. Such a film will only be fully effective when it is continuous, and therefore it will have a much greater effect in lowering surface tension when its area of distribution is relatively small. Since the constricting force exerted by surface tension is equal to $2 T / R, T$ being the surface tension and $\mathrm{R}$ the radius of an alveolus, small alveoli will, in the absence of surfactant, tend to deflate completely and large alveoli to expand at the expense of the smaller. This leads to uneven expansion of the lungs - in fact, to just the coincidence of atelectasis and emphysema that is seen in respiratory distress. In normal lungs the film of lipoprotein reduces the force constricting the partially deflated alveoli while having little effect on the forces acting on expanded air sacs with their greater surface area, and thus its action is to stabilise the size of communicating alveoli and to prevent complete deflation. It is not clear whether deficiency of this substance is a cause or an effect of the other changes found in the lung in respiratory distress, nor whether it predisposes to the development of the condition or merely to a fatal outcome. Surfactant deficiency may be due to immaturity alone, but it is more likely that it results from denaturation by fibrin present in pulmonary oedema fluid formed at around the time of delivery. Whatever the cause, the deficiency must often be made good fairly rapidly since such a high proportion of affected infants recover within a few days.

\section{Clinical Features}

It is now clear that nearly all affected babies show some signs of asphyxia at binth and are obviously ill before they reach four hours of age : indeed it has been shown that the crying vital capacity is already reduced during this period. The cardinal signs are a rising respiration rate, inspiratory retraction, a grunt on expiration, oedema of the extremities, and a tendency to cyanosis and poikilothermia. Usually there is very little movement of the intercostal or accessory muscles, and consequently diaphragmatic contractions tend to suck in the chest wall rather than to fill the lungs, thus causing paradoxical movement of the chest and belly. This is a picture also seen in grown patients with a "stove-in" chest and in these circumstances also there is ventilatory insufficiency. Auscultation of the chest reveals faint and sobbing breath sounds of less duration than the inspiratory effort, and few or no added sounds; the percussion note is normal or "boxy"; the mediastinum remains central.

As regards the circulation, the pulse is usually weak, and fixed in rate: the apex beat may be displaced to the left; and the blood pressure tends to be low, with increased oscillometric excursions. There is only seldom gross enlargement of the liver.

In the 10 per cent of cases involving infants of more than $2500 \mathrm{~g}$. birth weight, the clinical picture may be rather different. Cardiac and hepatic enlargement are often gross enough to raise the suspicion of congenital heart disease: the breath sounds may be loud and harsh; and hypoxia is more marked than hypercapnia. In such cases the pH does not fall to the low levels seen in the distressed premature infant and death sometimes occurs as a result of hypoglycaemia. Tissue glycogen stores are found to be exhausted at post-mortem.

\section{$X$-ray Findings}

The appearance of the lungs in the skiagram may be diagnostic (though two films taken in quick succession often show very different patterns). Characteristically, the lungs have a reticulogranular appearance with air-filled bronchi outlined against more or less solid lung towards the hila (air bronchogram). The heart appears to be enlarged and rather inert. With time these abnormalities either disappear or in fatal cases progress until both lungs are solid with a more floccular pattern reminiscent of bronchopneumonia. Failure of gas to pass from the stomach to the intestines is associated with a fatal outcome.

Pathophysiology

Whatever the precipitating cause of the respiratory distress syndrome, in the developed disease it is clear that the essential disturbanoes are:-

(i) Pulmonary hypoperfusion with reversion to the foetal circulatory pattern in which the major and minor circulations are in parallel rather than in series. 
(ii) Progressive pulmonary collapse with loss of the normal functional residual capacity.

These changes greatly increase the work of breathing while rendering the lungs relatively inefficient in gas exchange, even when adequately ventilated, because they are inadequately perfused. The consequences are hypoxaemia, hypercapnia, a metabolic acidosis due largely to the accumulation of lactic acid from anaerobic glycolysis and rapid exhaustion of the available sources of energy. These changes lead in turn ito alterations in blood chemistry of which a progressive fall in $\mathrm{pH}$ and rise in potassium are the most important and characteristic.

Hypoperfusion. If the oxygen concentration in the inspired air is raised to above 40 per cent the rise in partial pressure that results is sufficient to overcome any conceivable deficiency of ventilation or barrier to diffusion; consequently, the persistence of cyanosis or, more accurately, failure to achieve normal oxygen saturation, in a baby breathing pure oxygen, indicates that blood is effectively by-passing the ventilated parts of the lung. It has been shown that in babies not responding to oxygen given at concentrations of up to 100 per cent, the oxygen saturation of blood in the umbilical arteries is well below 100 per cent, and it therefore follows that the circulation of such babies exhibits a physiological shunt past the ventilated portions of the lung. Whether this shunt is via the ductus, through the foramen ovale, or in unperfused parts of the lung, has not been shown; but since it has been quite clearly demonstralted in the foetal lamb that ventilation with 100 per cent $\mathrm{N}_{2}$ or 10 per cent $\mathrm{CO}_{2}$ in air causes a sharp increase in resistance to blood flow through the lung, whereas, under the same conditions, the ductus would tend to remain open, it is reasonable to speculate that in severe respiratory distress syndrome there may be a return to the foetal pattern of circulation. The degree of shunting has a considerable bearing on the prognosis, those infants in whom the $\mathrm{PaO}_{2}$ cannot be raised to more than $100 \mathrm{~mm}$. $\mathrm{Hg}$. in 100 per cent environmental oxygen in the initial stages (3-6 hrs.) having an 80 per cent mortality, the remainder a relatively favourable outlook.

Collapse. Application of the techniques of respiratory physiology to the baby with respiratory distress has revealed the functional corollaries of the absence of surfactant found at post-mortem: compliance is decreased; the respiration rate must be increased to ensure a normal minute volume in the face of a reduced tidal volume: and the functional residual capacity is reduced to the point where the baby may have to re-inflate rather than expand the alveoli with each inspiratory effort, thus greatly increasing the work of breathing. Failure to comply with these demands results in progressive respiratory and circulatory failure-the latter with the features of shock rather than cardiac failure as conventionally understood; and the infanit finally dies of exhaus- $\cong$ tion when he can no longer maintain the high 3 respiration rate necessary for adequate ventilation $\stackrel{\mathbb{Q}}{\varrho}$ or create the high negative pressures needed to $c$.

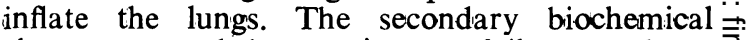
changes caused by respiratory failure, such as $\stackrel{0}{\rightarrow}$ acidaemia, hyperkalaemia and hypoglucosaemia, $\overline{0}$ contribute to a vicious circle and may be the 음 immediate cause of death in fatal cases.

\section{Treatment}

Prevention of respiratory distress is an obstetric problem that must wait upon a proper under- $\vec{\circ}$ standing of its aetiology, but as a first principle babies at risk should be effioiently resuscitated at $\vec{\omega}$ binth and it may be good policy to inflate the o lungs mechanically even when spontaneous respira- $\frac{0}{2}$ tion is quickly established. There is some evidence 3 . that the pulmonary hypoperfusion characteristic if cf severe cases can be permanently reversed by the intravenous injection of the organic alkali $\underset{\infty}{\infty}$ THAM (Tris-hydroxy methyl-amino-methane) $\dot{\omega}$ early in the course of the illness, and this measure $\infty$ should be tried in all cases where the $\mathrm{PaO}_{2}$ at $\mathrm{O}$ 3-6 hours indicates the presence of a large shunt. Apart from these measurements, treatment is desiderata:-

(i) Maintenance of adequate oxygenation.

(ii) Maintenance of body temperature.

(iii) Maintenance of acid/base balance.

(iv) Maintenance of energy requirements.

(v) Prevention of infection.

(vi) Attention to other adverse factors such as jaundice.

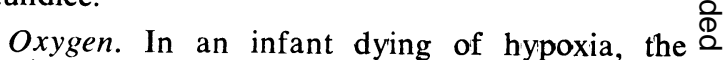
obvious treatment would seem to be to raise $\overrightarrow{\overrightarrow{0}}$ the ambient oxygen concentration, but since even 100 per cent oxygen does not in severe cases achieve full arterial oxygen saturation, and since such concentrations are dangerous to infants who do not need them (predisposing to retro-lental 3 fibroplasia and possibly damaging the lungs), even vulnerably distressed infants have not been cus- 3 tomarily nursed in an atmosphere containing more than 40 per cent oxygen at atmospheric pressure. Avery has shown that this cautious overall policy may have led to an increase in the death rate in Baltimore and Gairdner has pointed out $I$ that increasing the ambient $\mathrm{O}_{2}$ concentration above 40 per cent raises the arterial oxygen satura- $N$ tion of severely distressed babies by a significant amount by increasing the quantity of oxygen $N$ dissolved in the plasma of that fraction of blood N which comes into contact with alveolar gas. It is clear that some severely distressed babies ought to be nursed in high oxygen concentrations, but it is difficult to steer between the Scylla of $\mathbb{D}$ blindness and the Charybdis of unnecessary death or brain damage from hypcxia. Since the skin colour is a very poor guide to oxygenation in infants (due to sluggish circulation through the skin) and since both hypoxaemia and hyperoxae- 
mia are dangerous at that time of life, there seems no safe alternative to direct measurements of $\mathrm{PaO}_{2}$ in infants at risk; and fortunately this is comparatively easily achieved in the new-born by catheterisation of the umbilical arteries. Instruments are now available for the direct measurement of $\mathrm{PO}_{2}, \mathrm{PCO}_{2}$ and $\mathrm{pH}$ in small samples of arterial blood which can be obtained from the aorta via an indwelling catheter. This can be safely left in place for at least 48 hours provided that certain precautions are observed for the prevention of haemorrhage, thrombosis and sepsis, so permitting repeated monitoring of the arterial blood during the serious phase of the illness and the adjustment of the inspired oxygen concentrations to the needs of the infant as revealed by the $\mathrm{PaO}_{2}$.

As regards artificial ventilation, this is being used in several centres but the results do not so far appear to be promising. It is more than likely that assisted positive pressure ventilation can (in the presence of a collapsible chest wall) achieve better gas exchange than the infant can manage by his own efforts, but IPPR necessitates a tracheostomy or prolonged intubation, careful monitoring, and very lavish nursing care, and to treat all dyspnoeic babies in this way would almost certainly over-tax the resources of most neonatal departments. Those interested in this approach would be well advised to study the circulatory effects of prolonged positive pressure respiration, which might be expected to trap venous blood below the diaphragm and so aggravate circulatory failure with pulmonary hypoperfusion.

Acid-base Balance. Dr. Robert Usher of Montreal has been the pioneer in attempting to correct the secondary biochemioal disturbances of respiratory distress by the infusion of glucose and buffer intravenously. It is his thesis that the immediate cause of death in fatal cases may be the associated hyperkalaemia and acidaemia resulting from tissue breakdown and glycolysis, and that if these are corrected the infant may survive until natural recovery supervenes.* In acutely asphyxiated new-born animals Dawes and his colleagues have shown very clearly that a mixture of glucose and alkali will prolong survival whereas either used alone has no effect: it therefore appears likely that in some cases metabolism is brought to a standstill by its own acid end-products and that when the $\mathrm{pH}$ is even partially corrected the baby may be able to make use of infused carbohydrate which would otherwise go to waste. In this connection it is interesting that there is often a terminal hyperglycaemia and hyperphosphataemia. The regime recommended by Dr. Usher is the infusion of a solution containing 5-10 per cent glucose and $40 \mathrm{mEq}$ of sodium bicarbonate per litre by scalp vein at an approximate rate

\footnotetext{
*Recently it has been shown that surfactant synthesis is temperature and $\mathrm{pH}$ dependent.
}

of $65 \mathrm{ml} . / \mathrm{kg}$./day, with frequent monitoring of $\mathrm{pH}$ during treatment and of blood glucose when it is discontinued. The aim is to maintain a near normal $\mathrm{pH}$ and to supply the baby as nearly as possible with his caloric needs. The water and sodium overload entailed appears to be well tolerated by most infants. More recently Hutchinson and his colleagues from Glasgow have claimed very good results following introduction of a similar regime. They employ larger quantities of buffer in an attempt to correct the calculated buffer-base deficit from hour to hour and use fructose rather than glucose as a source of energy. While it is true that fructose can be tolerated in much higher concentrations than glucose because it is less irritating to vein walls, there is no certainty that it can be completely metabolised in the premature infant and some evidence that it causes lacticacidaemia.

Maintenance of Body Temperature. In a series of important papers Silverman and his colleagues have shown that the prognosis in premature infants with or without respiratory distress is improved 'when they are kept warm; other observers have shown that it is adversely affected when they are deliberately cooled.* The neutral temperature zone (that at which oxygen consumption is normal) is very high in immature infants and approaches the normal body temperature, while the metabolic response to cold is inhibited by hypoxaemia. Clearly premature infants should not be allowed to get cold at the time of delivery, when they are exposed while wet to relatively low environmental temperatures; and subsequently they should be nursed in incubators at environmental temperatures of between 32 and $35^{\circ} \mathrm{C}$ with precautions against loss of radiant heat. The maintenance of a high relative humidity helps to minimise loss of heat and water via the breath and skin

Energy Requirements. Respiratory distress increases the work of breathing and premature birth cuts short the normal accumulation of food stores in the foetus: it is therefore logical to feed affected infants early by whatever route is practicable. Usually this can be achieved by frequent small feeds of undiluted breast milk given through an indwelling nasal oesophageal or gastric tube, but when this cannot be tolerated, babies can be fed intravenously as described above with concentrated hexose solutions. Administration of cortisol and glucagon appears to promote gluconeogenesis and helps to prevent hypoglycaemia. Suitable quantities are:-

(i) Breast milk- $50 \mathrm{ml} . / \mathrm{kg}$. on day one, given one or two hourly, $100 \mathrm{ml} . / \mathrm{kg}$. on day two, 150 $\mathrm{ml} . / \mathrm{kg}$. on day three.

(ii) Ten per cent glucose, or 30 per cent hexose (glucose and fructose and galactose) at a rate of $165 \mathrm{ml}$. $/ \mathrm{kg}$.-24 hours, given by scalp vein drip.

(iii) Cortisol. $10 \mathrm{mg} . / \mathrm{kg}$./day i.m.i. $6 \mathrm{hrly}$.

(iv) Glucagon. $0.12 \mathrm{mg} . / \mathrm{kg}$./day i.m.i. 6 hrly. 
Prevention of Secondary Infection. The routine use of so-called prophylactic antibiotic regimes in uninfected infants is now in disrepute, but some babies with respiratory distress undoubtedly develop secondary pneumonia which may only be diagnosed at post-mortem.

Babies of under 32 weeks' gestation nearly always have dangerously low levels of gamma globulin and should be given $250 \mathrm{mg}$. of pooled adult gamma globulin soon after birth to raise them to safe levels. Any suspicion of infection in a premature baby-such as unexpected deterioration, the appearance of rales in the chest, etc. -should lead to energetic investigation and treatment. Since almost any organism may be pathogenic in these circumstances, it is wise to use an antibiotic cocktail which should include drugs active against (i) pyogenic cooci including penicillin-resistant strains. (ii) gram-negative organisms such as Proteus and E. Coli. (iii) B. pyocyaneas and (iv) Listeria. Suitable mixtures would be methicillin, ampicillin and polymyxin, or kanamycin, polymyxin and penicillin $G$.

Jaundice. Babies in respiratory failure appear to develop kernicterus at lower plasma levels of bilirubin than healthy infants: therefore exchange transfusion should be contemplated at levels 25 per cent lower than those that are customary in the department concerned-If acid-citrate-dextrose blood is used, its acidity should be corrected with THAM immediately before use: if heparinised blood is employed, appropriate doses of protamine should be given.

Heart Failure. Babies with respiratory distress nearly always exhibit both pulmonary and peripheral oedema; blood potassium levels are high; and their hearts are usually enlarged. There would seem to be a case for the routine administration of digitalis and a diuretic but there is no convinicing published evidence that either measure is beneficial.

Intraventricular Haemorrhage. About one-third of babies dying with evidence of the pulmonary syndrome exhibit bleeding into the cerebral ventricles at post-mortem: reciprocally, about onethird of babies dying of intraventricular haemorrhage have the pulmonary syndrome. In the author's opinion there is no causal relation between these entities, which are probably associated because they both occur most commonly in infants of low gestational age dying in the first week of life. The oocurrence of intracranial haemorrhage in a baby with the respiratory distress syndrome is signalled by attacks of apnoea, increased shunting and a sharp fall in $\mathrm{Hb}$ level, and foreshadows a fatal outcome in most cases.

Pneumothorax. A rare but serious complication of respiratory distress is the development of a spontaneous pneumothorax. This causes a sudden deterioration in an infant till then holding its own, and should therefore always be suspected in such circumstances. The diagnosis can be confirmed by X-ray (taking care not to be confused by the prominent muscle line to be seen running obliquely across the lower zone of the right lung in most X-rays of premature infants) and it may be necessary to decompress the pleura via a trocar, cannula and water seal if high environmental oxygen concentrations do not correct hypox'aemia.

\section{(3) Pneumonia}

Death from pneumonia in the newly born is almost as common as from the respiratory distress syndrome but the term is a loose one that includes a number of different entities.

(i) Aspiration pneumonia-The aspirate being blood, meconium, maternal pus, infected liquor, mucus, etc., from the birth canal, usually occurring as a complication of birth asphyxia, or the infant's own secretions.

(ii) True infective pneumonia-Again probably caused by aspiration in the birth canal.

(iii) Secondary pneumonia-Complicating other conditions such as respiratory distress or congenital anomalies.

(iv) Silent pneumonia in very small babiesUsually found at post mortem.

Aspiration pneumonia usually manifests itse1 by respiratory distress, but in contrast to the respiratory distress syndrome, it affects mainl term infants, is characterised by coarse added sounds in the chest and coarse shadowing on the $X$-ray film, and very seldom shows any latent phase after birth. Heart failure is a frequent complication but shunting is less than in the R.D.S. The most serious complication is the develcpment of pneumomediastinum and pneumothorax, which is foreshadowed by characteristic changes in the lateral chest films. Such infants should be nursed in very high oxygen concentrations and may require emergency pleural decompression via an underwater seal. Antibiotics should be given because there is usually an infective element. Prognosis is bad.

True pneumonia can develop precociously, the clinical picture resembling R.D.S., in which case the responsible organism is usually penicillin sensitive (streptococcus, pneumococcus or listeria).

\section{(4) Recurrent Apnoea}

Premature infants who do not develop or who survive the respiratory distress syndrome are liable to stop breathing from time to time for no obvious reason during the first few weeks of life. Usually an apnoeic attack is suoceeded, as one would expect, by spontaneous breathing or gasping, and nearly always cutaneous stimulation will initiate the first gasp, but a weak or siokly baby will often die of anoxia during an attack and there is evidence that the survivors may sustain severe brain damage. To prevent such casualties, the $\Rightarrow$ $\frac{10}{20}$ ๕ 
ratio of staff to patients in neonatal sick units needs to be high. The cause of these apnoeic attacks is not always clear, but it is likely that they can be precipitated by various factors such as aspirations of mucus, hypoglycaemia, hyperbilirubinaemia, cerebral bleeding, raised intracranial pressure, dehydration, hypoxia and infection. Premature infants often exhibit marked periodicity in their breathing; and though it has been shown that this does not reduce overall ventilation, it could initiate progressive collapse especially if high concentrations of environmental oxygen were used-and there is an additional danger of retrolental fibroplasia because between attacks respiration is efficient. The use of moderately increased environmental oxygen concentrations seems to reduce the frequency (though not the duration) of attacks of apnoea, requirements being gauged by the ability to produce a metabolic response to cold (which can be assessed by measuring differential skin temperatures in skin overlying brown and white fat respectively during exposure of the face to environmental temperatures of $80-85^{\circ} \mathrm{F}$ ).

Affected infants should be handled as little as possible but may require prolonged intubation and sometimes IPPR if spells are frequent and/ or prolonged.

\section{(5) Miscellaneous Conditions}

\section{The Wilson-Mikity Syndrome}

Occasionally a premature infant who has survived the early respiratory hazards of the newborn will develop chronic respiratory insufficiency with a particular X-ray picture and a need for increased environmental oxygen concentrations over a period of weeks or months. In fatal cases a rather characteristic microscopic appearance is seen in the lungs with thickening of interalveolar septa, fibrosis and chronic oedema. The aetiology is unknown.

\section{Plasma-cell Pneumonia}

A rather similar clinical picture is seen in infants infected with pneumocystis carinii, which has been responsible for epidemics of chronic pulmonary disease in new-born nurseries on the continenlt of Europe.

\section{Tension Cysts}

These are usually congenital in origin but may complicate pneumonia (particularly that caused by staphylococcal or Friedlander infection). Onset of symptoms is usually abrupt and may follow minor trauma: the baby becomes increasingly dyspnoeic and cyanosed and is found on examination to have the signs of a pneumothorax (which may indeed be present as a complication) with a hyperresonant chest, shift of the mediastinum to the opposite side and poor air entry. X-ray confirms the clinical diagnosis, showing replacement of normal lung by an air-filled cyst which may occupy almost the whole hemithorax. The infant should be nursed in high concentrations of oxygen while awaiting emergency surgery, the use of a trocar and cannula for decompression via an underwater seal being indicated when the infant's condition is desperate as a preliminary to operation. Results in survivors are good.

\section{Pseudo-bulbar Palsy}

Some babies appear unable to swallow much of their own secretions though there is no anatomical obstruction or cranial nerve paralysis. They tend to develop recurrent aspiration pneumonia and may have to be fed via a gastrostomy until they can take from a spoon. They are best nursed supine.

\section{Pulmonary Haemorrhage}

This is usually massive and of sudden onset and signs are therefore more often referred to the central nervous system than to the lungs. It is met with most commonly in underweight-fordates infants in whom it is associated with hypothermia and hypoglycaemia. If the baby survives the initial episode rales are found in the affected part of the chest and bloody froth may appear in the mouth. Treatment should be directed to maintenance of adequate ventilation, body temperature and blood glucose levels; the prognosis is bad.

\section{Pleural Effusions}

Effusions of blood, lymph or extra-cellular fluid into one or both pleural cavities cause respiratory distress which can only be relieved by drainage. For this reason all babies should have a satisfactory chest film taken as soon as the existence of respiratory distress is recognised. In many instances aspiration on a single occasion will produce permanent relief.

\section{Conclusion}

The new-born infant has poor respiratory reserves and is at risk from any condition which encroaches upon them. There are a number of illnesses affecting the respiratory tract which are only found in this age-group and which need to be understood by any physician responsible for the medical care of young infants.

\section{Review Articles}

\section{REFERENCES}

Avery, M. E. (1964): The Lung and its Disorders in the New-born Infant. (Major Problems in Clinical Paediatrics, Vol. I). Philadelphia and London: Saunders.

CoOK, C. D., Barrie, H., and Avery, M. E. (1960): Respiratory Problems in New-born Infants in Advances in Pediatrics. London: Lloyd Luke.

GAIRDNER, D. (1965): Respiratory Disorders in the New-born, in Recent Advances in Paediatrics. Ed. Gairdner. London: Churchill.

JAMES, L. S. (1963): Physiology of Respiration in New-born Infants and in the Respiratory Distress Syndrome, Pediatrics, 24, 1064. 
STRanG, L. B. (1963): Respira'tory Distress in Newborn Infants, Brit. med. Bull., 19, 45.

SWyER, P., and Levison, H. (1965): The Current Status of the Respiratory Distress Syndrome of the New-born, Canad. Med. Assoc. J., 93, 335.

\section{Introduction}

Butler, N. R., and Bonham, D. G. (1963): Perinatal Mortality. The First Report of the 1958 British Mortality Survey. Edinburgh and London: E. and S. Livingstone.

\section{Congenital Malformations}

Smithells, R. W. (1963): The Early Diagnosis of Congenital Abnormalities. London: Cassell.

Respiratory Distress Syndrome Aetiology

Cohen, M. M., Weintraub, D. H., and Lillenfeld, A. M. (1960): The Relation of Pulmonary Hyaline Membrane to Certain Factors in Pregnancy and Delivery, Pediatrics, 26, 42.

DAVIS, J. A., and STAFFORD, ANNE (1964): Respiratory Distress in Newborn Rabbits, Biol. Neonat., 7, 129.

DunN, P. (1965): The Respiratory Distress Syndrome of the New-born-Immaturity v. Prematurity. Arch. Dis. Childh., 40, 62.

Gellis, S., and HsiA, D. (1959): The Infant of the Diabetic Mother, Amer. J. Dis. Childh., 97, 1.

PotTer, E. L. (1963): Twin Zygosity and Placental Form in Relation to the Outcome of Pregnancy, Amer. J. Obstet. Gynec., 87, 566.

Reynolds, E. O. R., Jacobson, H. N., Motoyama, E. K., KikKaWa, Y., Craig, J. M., OrZalesi, M. M., and CooK, C. D. (1965): The Effect of Immaturity and Pre-natal Asphyxia on the Lungs and Pulmonary Function of New-born Lambs: The Experimental Production of Respiratory Distress, Pediatrics, 35, 382.

Usher, R. McLean, F., and Maugham, G. (1964): Respiratory Distress Syndrome in Infants Delivered by Caesarean Section, Amer. J. Obstet. Gynec., 88, 806.

VANLEEEWEN, G. (1965): Infants of Diabetic Mothers, Clin. Paed., 4, 315.

Pathology

Avery, M. E., and Mead, J. (1959): Surface Properties in Relation to Atelectasis and Hyaline Membrane Disease, Amer. J. Dis. Childh., 97, 517.

Bound, J. P., Butler, N. R., and Spector, W. G. (1956): Classification and Causes of Perinatal Mortality, Brit. med. J., ii, 191

Briggs, J. N., and HoGG, C. (1958): Perinatal Pulmonary Pathology, Paediatrics, 22, 41.

Claireaux, A. E. (1953): Hyaline Membrane in the Neonatal Lung, Lancet, ii, 749.

Clements, J. A. (1962): Surface Tension in the Lungs, Scientific American, 207, 120.

DESA, A. J. (1965): Microscopy of the Alveolar Lining Layer in New-born Infants, Lancet, i, 1369.

FARBER, S., and Wilson, J. L. (1933): Atelectasis of New-born-Study and Critical Review, Amer. J. Dis. Childh., 46, 572.

Gitlin, D., and Craig, J. M. (1956): Nature of Hyaline Membrane in Asphyxia of the New-born, Pediatrics., 17, 64.

Gruenwal.D, P. (1965): The Pathology of the Respiratory Distress Syndrome, Arch. Path., 80, 30.

Klaus, M. H., Clements, J. A., and Havel, R. J (1961): Composition of Surface Active Material Isolated from Beef Lung, Proc. Nat. acad. Sci., 47, 1858.
Pattle, R. E. (1965): Surface Lining of Lung Alveoli, Physiol. Revs., 45, 48.

ReYNOLDS, E. O. R., and StRaNG, L. B. (1966): Alveolar Surface Properties of New-born Lung, Brit. med. Bull., 22, 79.

TAYlOR, F. B., and ABRAMS, M. E., (1966): Effect $\vec{F}$ of Surface Active Lipo-protein on Clotting and Fibrinolysis, and of Fibrinogen on Surface Tension of Surface-active Lipo-protein-with a Hypothesis on the Pathogenesis of Pulmonary Atelectasis and Hyaline Membrane in the Respiratory Distress Syndrome of the New-born, Amer. J. Med., 40, 346.

Clinical Features

MilleR, H. C. (1962): Respiratory Distress Syndrome of New-born Infants. J. Pediat., 61, 2.

Rudolph, A. J., and Smith, C. A. (1960): Idiopathic Respiratory Distress Syndrome of the New-born. J. Pediat., 57, 905. $X$-ray Findings

Donald, I., and Steiner, R. J. (1953): Radiology it in the Diagnosis of Hyaline Membrane, Lancet, ii, 846. Pathophysiology

BlystaD, W. (1956): Blood Gas Determinations in Premature Infants. II Investigation of Premature Infants with Early Neonatal Dyspnoea (Hyaline Membrane Syndrome), Acta. Paed., 45, 103.

Burnard, E. D. (1959): Changes in Heart Size in the Dyspnoeic New-born Baby, Brit. med. J., i, 1494.

Chu, J., Clements, J. A., Cotton, E., Klaus, M. H $\vec{\emptyset}$ SweET, A. Y., Thomas, M. A., and ToOley, W. F (1965): The Pulmonary Hypoperfusion Syndrome Pediatrics, 35, 733.

DAwES, G. S. (1966): Pulmonary Circulation in the Foetus and New-born, Brit. med. Bull., $22,61$.

KarlberG, P., CoOK, C. D., O'Brien, D., Cherry, R. B., and Smith, C. A. (1954): Studies of Respiratory Physiology in the New-born Infant, Acta. Paed. (Uppsala) Suppl., 100.

Moss, A. J., Emmanouilides, G. C., Retton, O., Higashino, S. M., and Adams, F. H. (1965): Postnatal Circulatory and Metabolic Adjustments in Normal and Distressed Infants, Biol. Neonat., 8, 177.

Nicolopoulos, B. A., and Smith, C. A. (1961): Metabolic Aspects of the Idiopathic Respiratory Distress in New-born Infants, Pediatrics., 28, 206.

Rudolph, A. M., Drorbaugh, R. J. E., Auld, P. A., RudolPh, A. J., Nadas, A. S., Smith, C. A., and Hubbell, J. P. (1961): Study of the Circulation in the Neonatal Period-the Circulation in the Respiratory Distress Syndrome, Pediatrics, 27, 551.

RUdolPH, A. M., and YUAN, S. (1966): Response of the Pulmonary Vasculature to Hypoxia and $\mathrm{H} / \mathrm{T}$ on Changes, J. Clin. Invest., 45, 399.

Stahlman, M. (1964): Treatment of Cardio-Vascular Disorders of the New-born, Pediat. Clin. N. Amer., 11, 363.

StranG, L. B., and MacLeish, M. H. (1961): Respiratory Distress in New-born Inflants: Ventilatory Failure and Righ't to Left Shunt in New- 0 born Infants with Respiratory Failure, Pediatrics, 28, 17. Treatment (Maintenance of Oxygenation)

AVERY, M. E., and OPPENHEIMER, E. H. (1960): Recent Increase in Mortality from Hyaline Membrane Disease, J. Pediat., 57, 553. 
Boston, R. N., Geller, F., Cassidy, G., and Smith, C. A. (1964): Arterial $\mathrm{PO}_{2}$ and $\mathrm{pH} \longrightarrow$ An Accurate Guide to the Prognosis and Management of the Respiratory Distress Syndrome, J. Pediat., 65, 1043.

Gupta, J. M., Dahlenburg, G. W., and Davis, J. A. (1966): The Use of THAM in the Treatment of the Respiratory Distress Syndrome in the Newborn. (In Press).

Klaus, M. (1965): Prolonged Respirator Use in Pulmonary Insufficiency of New-born, J. Amer. med. Ass., 193, 183.

TizarD, J. P. M. (1964): Indications for Oxygen Therapy in the New-born, Pediatrics, 34, 771.

WARLEY, IM. A., and GaIRDNER, D. (1962): Respiratory Distress Syndrome of the New-bornPrinciples in Treatment, Arch. Dis. Childh., 37, 455.

\section{Treatment (Maintenance of body temperature)}

Day, R. L., Caliguiri, L., Kamenski, C., and EHRLICH, F. (1964): Body Temperature and Survival of Premature Infants, Pediatrics, 34, 171.

SCOPES, JON W. (1966): Metabolic Rate and Temperature Control in the Human Baby, Brit. med. Bull., 22, 88

Silverman, W. A., Fertig, J. W., and Berger, A. P. (1958): The Influence of the Thermal Environment upon the Survival of Premature Infants, Pediatrics, 22, 876

\section{Treatment (Acid base Balance)}

Dawes, G. S., Motr, J. C., Shelley, H. J., and Stafford, A. (1963): The Prolongation of Survival Times in Asphyxiated Immature Foetal Lambs, $J$. Physiol. (Lond.), 168, 43.

Hutchison, J. H., KerR, M. M., Douglas, J. A., Wall, J. A., and Crosbie, J. C. (1964): A Therapeutic Approach to 100 Cases of the Respiratory Distress Syndrome of the New-born Infant, Pediatrics, 33, 956.

TECK, T. W. T. (1965): Respiratory Distress Syndrome of the New-born in Kandang Kerbau Hospital (Controlled Clinical Trial of Glucose and Bicarbonate Therapy), J. of Singapore Paed. Soc., 7, 44.

UsHeR, R. H. (1963): Reduction of Mortality from the Respiratory Distress Syndrome of Prematurity with Early Adminstration of IV Glucose and Sodium Bicarbonate, Pediatrics, 32, 966.

\section{Treatment (Energy Requirements)}

Shelley, H. B. (1964): Carbohydrate Reserves in the New-born Infant, Brit. med. J., i, 273.

Smallpiece, V., and Davies, P. A. (1964): Immediate Feeding of Premature Infants with Undiluted 3reast Milk, Lancet, ii, 1349.

\section{Treatment (Prevention of Infection)}

Davies, J. A., and Tizard, J. P. M. (1961): Practical Problems of Neonatal Paediatrics Considered in Relation to Animal Physiology, Brit. med. Bull., 17, 168.

GaIRdNer, D. (1965): In Recent Advances in Paediatrics. Chapter II. London: J. \& A. Churchill.

HARDIE, G., HEESE, G., and KENCH, J. (1965): Serum Protein in the Idiopathic Respiratory Distress Syndrome, Lancet, ii, 876.
Treatment (Other Adverse Factors)

Intraventricular haemorrhage

GroNTOFT, O. (1954): Intracranial Haemorrhage and Blood Brain Barrier Problems in the New-born, Acta. path. Microbiol. Scand., 34, Suppl., 100.

\section{Pneumonia}

Ahvenainen, E. K. (1957): Clinical Symptoms of Respiratory Disorders in New-born. I: Symptoms of Neonatal Pneumonia, Ann. Pediat. fenn., 3, 1.

Davies, P. A., and AHERne, W. (1962): Congenital Pneumonia, Arch. Dis. Childh., 37, 598.

JohNSON, W. C., and Meyer, J. R. (1925): A Study of Pneumonia in the Stillborn Newborn, Amer. J. Obstet. Gynec., 9, 151.

Moller, H. J. (1961): Perinatal Non-specific Pneumonias, Act. Obstet. Gynec. Scand., XL, 309.

\section{Recurrent Apnoea}

BLYSTAD, W. (1956): Blood Gas Determinations in Premature Infants. HII Investigation of Infants with Recurrent Attacks of Apnoea, Acta. Paediat. (Uppsala), 45, 211.

GuPTA, J. M. (1966): Blood Gas Tensions and Acid-base Balance in New-born Infants with Apnoeic Attacks. To be published.

Reid, D., and Michell, R. (1966): Recurrent N6 )natal Apnoea, Lancet, i, 786.

STILL, G. (1923): Attacks of Arrested Respiration in the New-born, Lancet, 204, 431.

\section{Wilson-Mikity Syndrome}

Baghdassarian, O., Avery, M. E., and Neuhauser, E. B. D. (1963): A Form of Pulmonary Insufficiency in Premature Infants, Amer. J. Roentgenol., 89, 1020.

Wilson, M. G., Mikity, V. G. (1960): A New Form of Respiratory Disease in Premature Infants, Amer. J. Dis. Childh., 99, 489.

\section{Plasma-cell Pneumonia}

Ahvenainen, E. K. (1957): Interstitial Plasma Cell Pneumonia, Ped. Clin. N. Amer., 2, 203.

GajduseK, D. C. (1957): Pneumocystis CariniiEtiologic Agent of Interstitial Plasma Cell Pneumonia of Premature and Young Infants, Pediatrics, 19, 543.

\section{Pseudo-bulbar Palsy}

Ardran, G. M., Benson, P. F., Butler, N. R., Ellis, H. L., and MCKENDRICK, T. (1965): Congenital Dysphagia Resulting from Dysfunction of the Pharyngeal Musculature, Dev. Med. and Child. Neurol., 7, 157.

\section{Pulmonary Haemorrhage}

Ahvenainen, E. K. (1956): Massive Pulmonary Haemorrhage in the New-born, Ann. Pediat. fenn. 2, 44 .

\section{Pleural Effusion}

Perry, R. E., Hodgman, J., and Cass, A. (1963): Pleural Effusion in the Neonatal Period, J. Pediat., $62,838$.

StePhan, W., and Olfo, M. I. (1961): Pleural Effusion as a Cause of Respiratory Distress in Newborn Infants, J. Amer. med. Ass., 176, 615 . 